\title{
Impact Analysis of Damping Resistors in Damped Type Double Tuned Filter on Network Harmonic Impedance
}

\author{
R.Madhusudhana Rao \\ Assistant Professor, Electrical and Electronics Department \\ $V R$ Siddhartha Engineering College, Vijayawada, AP, India. \\ Mrutyunjay Mohanty \\ Senior Engineer, R\&D Department \\ Power Research \& Development Consultants Pvt. Ltd., Bengaluru, Karnataka, India. \\ Vemula Mahesh Veera Venkata Prasad \\ M.Tech Student, Electrical and Electronics Department \\ $V R$ Siddhartha Engineering College, Vijayawada, AP, India.
}

\begin{abstract}
In recent years the usage of power electronics equipment and non-linear elements increased in various areas of power system. Power systems contain considerable levels of harmonics which cannot be ignored further because there is considerable effects on power system equipment due to the harmonics. The filters are useful to eliminate harmonics and provide reactive power compensation. Double tuned filter is the type of passive filters have been widely using in Industries and HVDC stations. This paper proposed the design procedure for the parameters of the damped type double tuned filter based in the tuned frequencies and parallel resonance frequency and reactive power demand and voltage of the network. This paper deals with the effect of damping resistors connected in different configurations on the network impedance. To find the parameters a program has been developed in MATLAB-2015b. The performance of the filter parameters are verified by using MiPower 9.1.
\end{abstract}

Keywords: Harmonics, Mitigation techniques, Harmonic distortion, Double tuned passive filters, Damped resistors.

\section{INTROUDCTION}

With the growing usage of nonlinear loads and power electronic equipment in the power system there is a great concern about power quality issues particularly harmonic distortion. The harmonic distortions in the voltage and current waveforms in the power system are increasing continuously due to these nonlinear equipment. These harmonics may produce undesirable effects on various type of equipment which are present in power system and communication systems[1]-[4]. So it is very important to reduce the harmonic content produce by nonlinear to avoid the damage of the utility equipment. To eliminate harmonics so many techniques are proposed. Filter design is the most old and popular mitigation technique used in industries. The In this paper passive filters design mainly damped type double tuned filter is design is presented. The estimation of double tuned filter parameters from the two parallel single tuned filter bank is proposed in [7].In this paper algorithm-2 is adopted from [8] and algorithm-1is adopted from [6].

\section{BASIC DOUBLE TUNED FILTER}

Passive filters are the circuits with $\mathrm{R}, \mathrm{L}$ and $\mathrm{C}$ elements connected in different ways to eliminate desired harmonics by providing an alternative path to the harmonic currents. This passive filter technique is much popular, simple and easier than the advanced harmonic reduction techniques like PWM static VAR compensators and magnetic flux compensation, Active filters. Single tuned (ST) filters, Double tuned (DT) filters, and C-type filters are different type of passive filters. Double tuned filter is combination of one series resonant circuit and one parallel resonant circuit and it is used to eliminate two harmonic frequencies at a time. Generally To eliminate two harmonic frequencies at a time then two ST filters are required. The equivalent 
impedances of two single-tuned filters near their resonance frequencies are practically the same as the basic double tuned filter configuration.

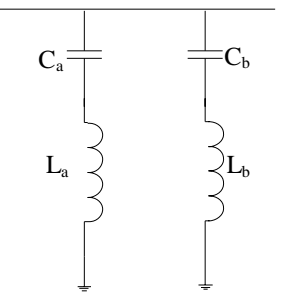

Figure.1. Two parallel single tuned filters

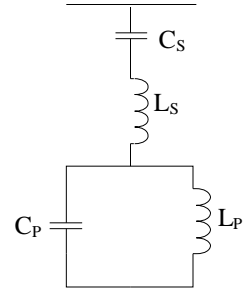

Figure.2.Double tuned filter

The basic double tuned filter is practically equal to the parallel branch of two single tuned filters. Hence the calculation of double tuned filter parameters has been done by equating the impedance of basic double tuned filter and parallel connection of two single tuned filters. The total impedance of the parallel connection of two single tuned filters has been written as

$$
Z(\omega)=\left(j \omega L_{a}+\frac{1}{j \omega c_{a}}\right) \|\left(j \omega L_{b}+\frac{1}{j \omega c_{b}}\right)
$$

The total impedance of the basic double tuned filter has been written as

$$
Z(\omega)=j \omega L_{g}+\frac{1}{j \omega C_{s}}+\frac{j \omega z_{p}}{1-\omega^{2} L_{p} C_{p}}
$$

By equating (1) and (2), the series branch parameters $\left(L_{5}, C_{5}\right)$ and parallel branch parameters $\left(L_{F}, C_{F}\right)$ of the double tuned filter can be expressed as

$$
\begin{aligned}
& t_{s}=L_{a}+L_{b}^{-} \\
& L_{g}=\frac{l_{m} L_{b}}{L_{s}+L_{B}} \\
& c_{p}=\frac{Q_{n} C_{h}\left(C_{n}+C_{n}\right)\left(L_{n}+L_{n}\right)^{2}}{\left(c_{a} L_{a}-C_{b} L_{B}\right)} \\
& L_{p}=\frac{\left(c_{a} L_{a}-c_{b} L_{b}\right)^{2}}{\left(a_{x}+L_{b}\right)\left(c_{x}+c^{2}\right.}
\end{aligned}
$$

Where $L_{a}, L_{b}, C_{a}, C_{b}$ are the parameters of two individual single tuned filters. By using (3), (4), (5), (6) the parameters of the filters are tuned for the particular harmonic order with particular reactive power and bus voltage. From the above design it is not possible to choose the particular parallel resonant frequency.so a method is proposed in [8] to determine the parameters of the double tuned filter by choosing the desired parallel resonance.

\section{ALTERNATIVE DESIGN OF DOUBLE TUNED FILTER BY CHOOSING THE PARALLEL RESONANCE FREQUENCY}

In conventional design procedure of filter which is previously explained in section II there has been no choice to choose the intermediate frequency between interested tuned frequencies. If any harmonic frequency between the two selected tuned frequencies is causing severe harmonic injections into the system these harmonic contents can be minimized by reducing the filter impedance at that frequency. Because normally at parallel resonance frequency the impedance is very high. An alternative approach has been designed to shift the parallel resonance point to reduce the harmonic content. The procedure to determine the parameters using parallel resonance frequency has been explained in this paper. From the basic double tuned filter the impedance of the series and parallel circuits are $Z_{s}(\omega), z_{p}(\omega)$ respectively

$$
\begin{aligned}
& Z_{s}(\omega)=j \omega L_{g}+\frac{1}{j \omega c_{p}} \\
& Z_{p}(\omega)=j \omega L_{p} \| \frac{1}{j \omega S_{p}} \\
& Z_{p}(\omega)=\frac{j \omega L_{p} \frac{1}{j \omega c_{p}}}{j \omega L_{p}+\frac{1}{j \omega c_{p}}}=\frac{j \omega L_{p}}{1-\omega^{2} z_{p} c_{p}}
\end{aligned}
$$

Where $\omega$ is the angular frequency and the series resonant frequencies of the series and parallel circuits respectively 


$$
\begin{aligned}
& \text { Series resonant frequency } \omega_{3}-\frac{1}{\sqrt{l_{s} C_{s}}} \\
& \text { Parallel resonant frequency } \omega_{p}=\frac{1}{\sqrt{L_{v} c_{v}}}
\end{aligned}
$$

When $a<m_{s}$ the series circuit impedance $\left(Z_{s}(\omega)\right)$ is capacitive and when $u>m_{s}$ the series circuit impedance is inductive. When $\omega<\omega_{p}$ the parallel circuit impedance $\left(Z_{F}(\omega)\right)$ is inductive and when $\omega>\omega_{2}$ the parallel circuit impedance $\left(Z_{F}(n)\right)$ is capacitive

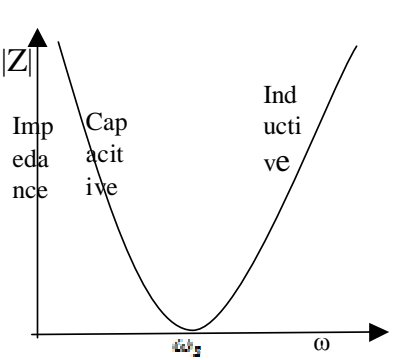

(a)

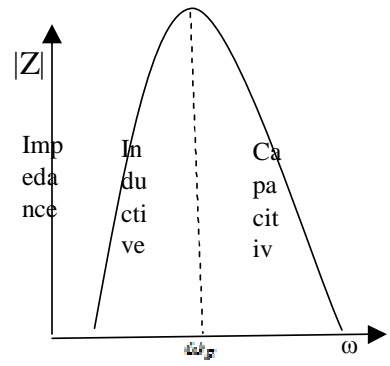

(b)

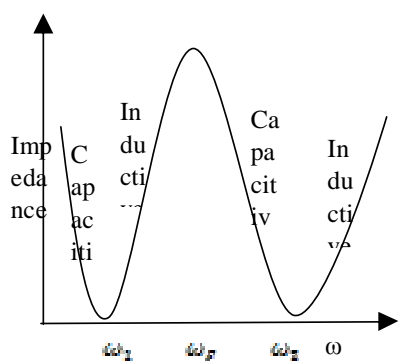

(c)

Figure.3. (a) Characteristics of the series branch of double tuned filter (b) Characteristics of the parallel branch of double tuned filter (c) Characteristics of the double tuned filter

The total impedance of the basic double tuned filter $Z(\omega)$ is

$$
Z(\omega)=Z_{S}(\omega)+Z_{F}(\omega)
$$

The total Thevinin impedance of double tuned filter at the tuned frequencies is zero

$$
\begin{gathered}
Z(\omega)=j \omega L_{s}+\frac{1}{j \omega C_{s}}+\frac{j \omega L_{p}}{1-\omega^{2} L_{p} C_{p}}=0 \\
\Rightarrow \omega^{4} L_{s} L_{p} C_{s} C_{p}-\omega^{2}\left[L_{s} C_{s}-L_{p} C_{p}-L_{p} C_{s}\right]+1=0
\end{gathered}
$$

Let $\omega_{1}^{2}, \omega_{2}^{2}$ are the roots of above equation, then

$$
\begin{aligned}
& \omega_{1}^{2} \omega_{2}^{2}=\frac{1}{\sqrt{L_{s} L_{p} C_{s} C_{p}}} \\
& \omega_{1} \omega_{2}=\frac{1}{\sqrt{L_{s} C_{s}}} \frac{1}{\sqrt{L_{p} C_{p}}}=\omega_{s} \omega_{p} \\
& \Rightarrow \omega_{s}=\frac{\omega_{1} \omega_{2}}{\omega_{p}}
\end{aligned}
$$

From (16), the obtained relations are

$$
\begin{aligned}
& L_{v}=\left(\frac{\omega_{p}}{\omega_{1} \omega_{2}}\right)^{2} \frac{1}{v_{s}} \\
& L_{p}=\frac{1}{\omega_{v}^{2} c_{s}}\left(\frac{\omega_{1}^{2}+\omega_{2}^{2}-\omega_{p}^{2}}{\omega_{p}^{2}}-1\right)
\end{aligned}
$$

Besides filtering the harmonic current, the double tuned filter has another performance of supplying the reactive compensation power. If the network fundamental rated voltage is $\mathrm{V}$, and the fundamental reactive power supplied by the filter is $\mathrm{Q}$, then the impedance of the filter at fundamental frequency is

$$
\begin{aligned}
& Z\left(\omega_{F}\right)=\frac{-j \omega}{Q^{2}} \\
& Z\left(\omega_{F}\right)=j \omega_{F} L_{g}+\frac{1}{j \omega_{k} G_{x}}+\frac{1 \omega_{F} L_{p}}{1-\omega_{F}^{2} L_{p} C_{2}} \\
& C_{s}=\frac{-2}{v^{2}}\left[\omega_{F}\left(\frac{o_{F}}{\omega_{s} \omega_{2}}\right)^{2}-\frac{1}{\omega_{F}}+\frac{\left.\omega_{F}\left[\omega_{1}^{2}+\omega_{2}^{2}-\omega_{F}^{2}\right) \omega_{F}^{2}-\omega_{1}^{2} \omega_{2}^{2}\right]}{\omega_{S}^{2} \omega_{S}^{2}\left(\omega_{S}^{2}-\omega_{G}^{2}\right)}\right]
\end{aligned}
$$

By using the value $C_{g}$ then simply, obtain the remaining parameters $L_{g} C_{g}$. $L_{g}$. Finally the parameters of damped type double tuned filter are

$$
L_{s}=\left(\frac{\omega_{p}}{\omega_{1} \omega_{2}}\right)^{2} \frac{1}{c_{s}}
$$




$$
\begin{aligned}
& \left.L_{\mathrm{p}}={ }_{\omega_{\mathrm{p}}^{2} c_{s}}\left(\begin{array}{c}
\omega_{1}^{2}+\omega_{2}^{2}-\omega_{7}^{2} \\
\omega_{2}^{2}
\end{array}\right)-1\right) \\
& C_{\mathrm{p}}=C_{2}\left(\frac{\omega_{2}^{2}}{\omega_{1}^{2}+\omega_{2}^{2}-\omega_{F}^{2}-\omega_{2}^{2}}\right)
\end{aligned}
$$

In order to design the filter $\mathrm{C}_{S}$ has been calculated initially from the known quantities like network voltage, reactive power required for the network and tuned frequencies. $\mathrm{L}_{\mathrm{S}}, \mathrm{L}_{\mathrm{P}}, \mathrm{C}_{\mathrm{P}}$ are has to be calculated according to $(22-25)$.

\section{DAMPED TYPE DOUBLE TUNED FILTER}

The basic double tuned filter Thevenin impedance is almost pure inductive or capacitive in nature over the whole frequency range. If the system impedance is approximately equal in magnitude and conjugate to the impedance of the filter at some harmonic frequencies, as a result the network resonance will occur. Due to this resonance phenomenon the harmonic currents being severely amplified with the harmonic over voltage of the components in the filter and in power system. To prevent such a phenomenon, damping resistors are added to basic type of double tuned filter in different ways to obtain the different configurations of damped type double tuned filters. The characteristics and the performance of damped type double tuned filter will change with respect to the placing of damping resistor.

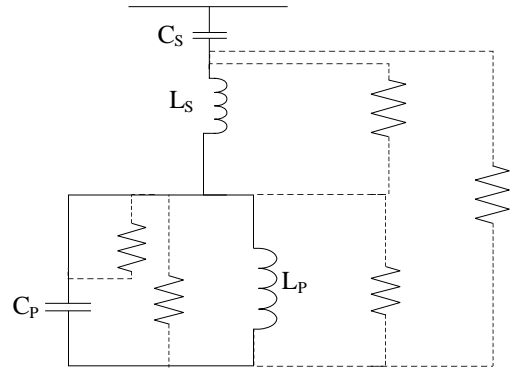

Figure .4. Damped type double tuned filter

Different configuration of damped type double tuned filter has been formed by inserting the damped resistor at different position in basic double tuned filter as showed in Figure.4.the various types of damped type double tuned filter configurations has been explained in section- $\mathrm{V}$. The procedure to determine the parameters of damped type double tuned filter is explained in a step by step process as follows.

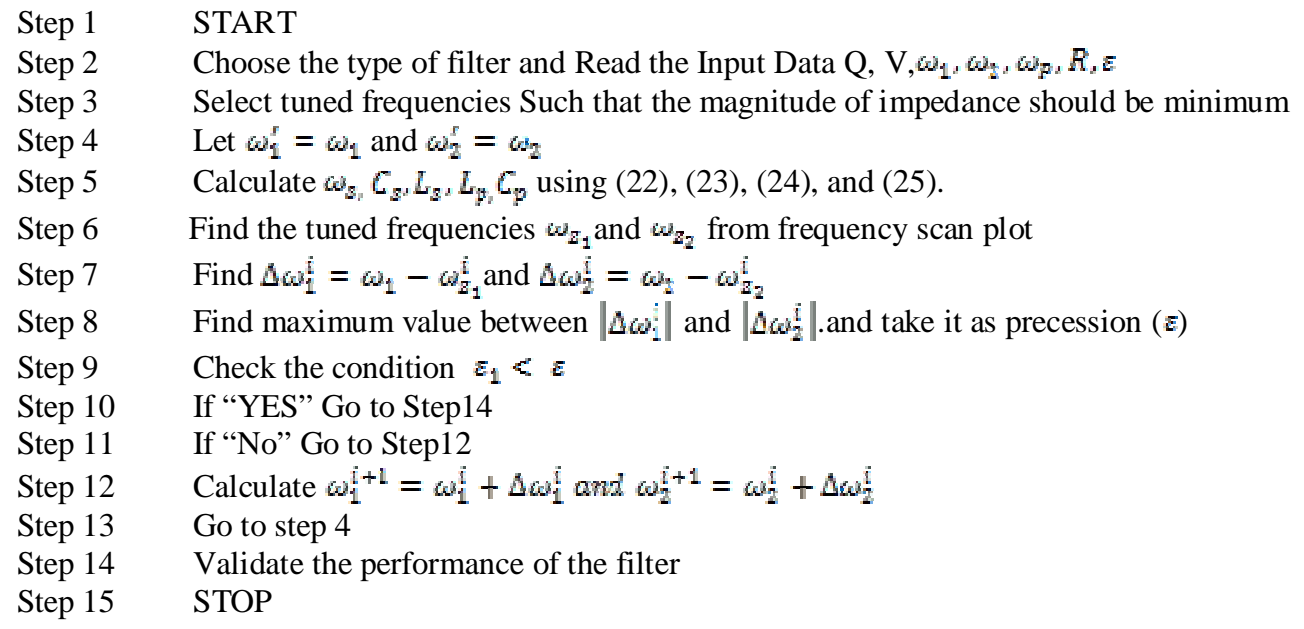

From the above procedure a program has been developed in MATLAB software to calculate filter parameters accurately. The filter parameter values and performance and impact of the designed filters are explained in detail in section $\mathrm{V}$. 


\section{CASE STUDY}

To analyse the different double tuned filters a test case is taken from [5]. The test system showed in Figure.5 consisting of $220 \mathrm{kV}$ generator having short circuit capacity of $4000 \mathrm{MVA} \mathrm{X} / \mathrm{R}$ ratio as 20 and 100 MVA, $220 \mathrm{kV} / 33 \mathrm{kV}$ step down transformer having \% impedance as 14 and $\mathrm{X} / \mathrm{R}$ ratio is 10 . This test system consisting linear load of 20MW and nonlinear load (adjustable speed motor drive) of $25 \mathrm{MW}$ installed at $33 \mathrm{kV}$ bus. 100 MVA \& $60 \mathrm{~Hz}$ are considered as the base quantities. A Shunt capacitor having a rating of 8.4 MVAR is also installed at the $33 \mathrm{kV}$ bus. The harmonic source in this case study is a standard diode rectifier supplying $25 \mathrm{MW}$ on the dc side. The harmonic content injected by the diode rectifier is tabulated in Table.1. The Harmonic analysis is carried out using MiPower software, with the load modelled as frequency dependent Reactance and constant Resistance (parallel combination) to find out impact of harmonic caused by diode rectifier. The performance of the designed damped type double tuned filters has been verified by using MiPower software. A frequency scan plots has been plotted for every configuration of filter.

Table.1. Harmonic currents injected by diode rectifier at $33 \mathrm{kV}$ bus

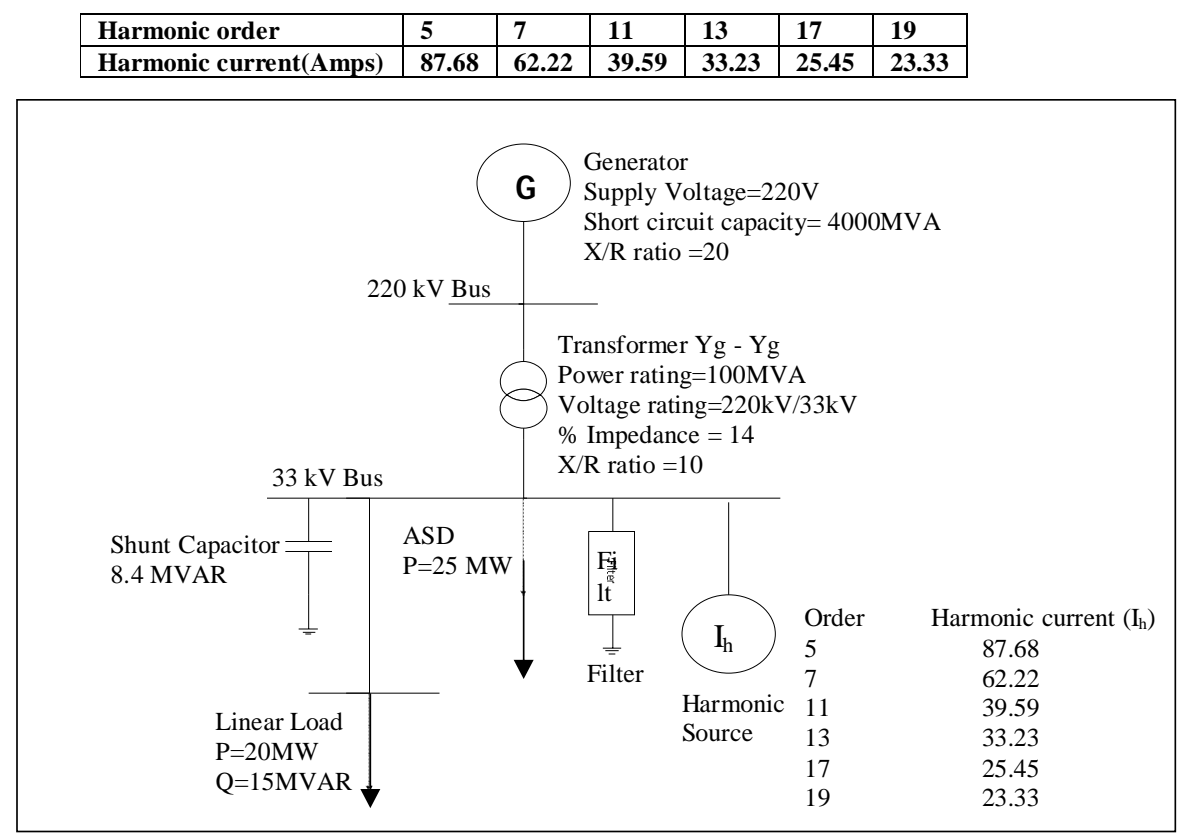

Figure .5. IEEE -319 Test system for harmonic analysis

The results obtained by performing the harmonic analysis on test system without filter and with the filters have been tabulated and also the variation of characteristics of different type of filters with respect to the variation in parallel resonance frequency also has been explained in this section. By performing the harmonic analysis using MiPower for the test system without any filter the results are tabulated in Table 2.

Table.2.Harmonic distortion at $33 \mathrm{kV}$ bus without filters

\begin{tabular}{|l|l|l|l|l|l|l|l|}
\hline \multicolumn{7}{|c|}{ \% Voltage harmonic distortions at 33kV bus without filter } \\
\hline Harmonic order & Total & 5 & 7 & 11 & 13 & 17 & 19 \\
\hline Harmonic distortion & 12.1820 & 5.7409 & $\mathbf{8 . 8 0 7 2}$ & $\mathbf{5 . 1 7 2 6}$ & $\mathbf{2 . 8 7 4 7}$ & $\mathbf{1 . 3 3 6 5}$ & 1.0335 \\
\hline
\end{tabular}

From the Table. 2 the harmonic distortions injected by $5^{\text {th }}, 7^{\text {th }}, 11^{\text {th }}$ order are deviating as per [1]. To eliminate these harmonic it is necessary to design the filter. This work is mainly focused on the different configurations of the damped type double tuned filter. Here the filters are designed for $5^{\text {th }}$ and $11^{\text {th }}$ order harmonics the reactive power has been taken as $8.4 \mathrm{Mvar}$ to design the harmonic filters which is previously supplied by capacitor. The filters are designed at $33 \mathrm{kV}$ bus voltage. The filter parameters for different configurations obtained through MATLAB programming using algorithm proposed in section- $\mathrm{V}$ is tabulated in Table 3 . The damping resistor value should be very high if the resistor is connected in parallel to the filter components, and the value of the 
resistor should low if the resistor is connected in series with filter elements. In order to satisfy these conditions in this paper the resistor values for different configuration of damped type double filters are tabulated in table.3.

Table.3.The Damped resistor values considered in different configurations of the damped type double tuned filter

\begin{tabular}{|c|c|c|c|c|c|c|}
\hline Filter type & 1 & 2 & 3 & 4 & 5 & 6 \\
\hline Damping Resistor value $(\mathrm{Ohm})$ & $\mathbf{5 0 0}$ & 500 & 500 & 0.2 & $R_{1}=500, R_{2}=500$ & $\mathbf{R}_{1}=500, \mathbf{R}_{2}=250$ \\
\hline
\end{tabular}

The designed parameters of the damped type double filter by varying the parallel resonance frequency in between $5^{\text {th }}$ and $11^{\text {th }}$ harmonic order frequencies are tabulated in table. 4 .

Table.4.Filter parameters of different configuration of filters

\begin{tabular}{|c|c|c|c|c|c|}
\hline \multirow{2}{*}{ Filter parameters } & \multirow{2}{*}{$\begin{array}{l}\text { Double tuned filter } \\
\qquad\left(5^{\text {th }}, 11^{\text {th }}\right)\end{array}$} & \multicolumn{4}{|c|}{ Damped type Double tuned filter $\left(5^{\text {th }}, 11^{\text {th }}\right)$} \\
\hline & & $N_{F}=7$ & $N_{p}=8$ & $N_{\bar{p}}=9$ & $N_{\bar{p}}=10$ \\
\hline $\mathbf{L}_{1}$ (Henry) & 0.0047762 & 0.0057315 & 0.0075226 & 0.0095525 & 0.011821 \\
\hline $\mathrm{C}_{1}($ Farad $)$ & $1.9967 \mathrm{e}-05$ & $1.9886 \mathrm{e}-05$ & $1.9789 \mathrm{e}-05$ & $1.9723 \mathrm{e}-05$ & $1.9677 \mathrm{e}-05$ \\
\hline $\mathbf{L}_{2}$ (Henry) & 0.0036369 & 0.0041249 & 0.0040827 & 0.0032613 & 0.0018618 \\
\hline $\mathrm{C}_{2}($ Farad $)$ & $4.7187 \mathrm{e}-05$ & $3.4812 \mathrm{e}-05$ & $2.6929 \mathrm{e}-05$ & $2.6635 \mathrm{e}-05$ & $3.7792 \mathrm{e}-05$ \\
\hline
\end{tabular}

The voltage harmonic distortions limits after installation basic double tuned filter is tabulated in Table.5.

Table.5. Impact of basic double tuned filter on $33 \mathrm{kv}$ bus

\begin{tabular}{|c|c|c|c|c|c|c|}
\hline \multicolumn{7}{|c|}{ \% Voltage harmonic distortions on $33 \mathrm{kV}$ bus } \\
\hline Total & 5 & 7 & 11 & 13 & 17 & 19 \\
\hline 5.3784 & $\mathbf{0 . 0 0 0 1}$ & 4.799 & 0 & 0.9755 & 1.5043 & 1.6378 \\
\hline
\end{tabular}

From the Table it is understand that the $5^{\text {th }}$ and $11^{\text {th }}$ order harmonics are eliminated after installation of basic type double tuned filter at $33 \mathrm{kV}$ bus.

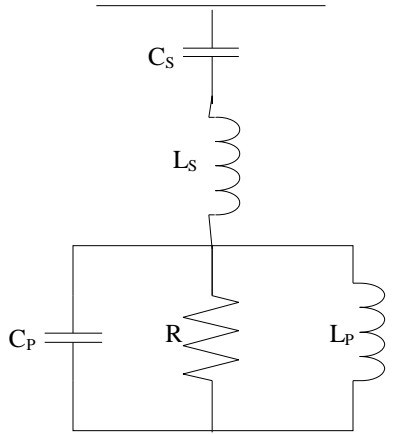

Figure.6. Filter (1)

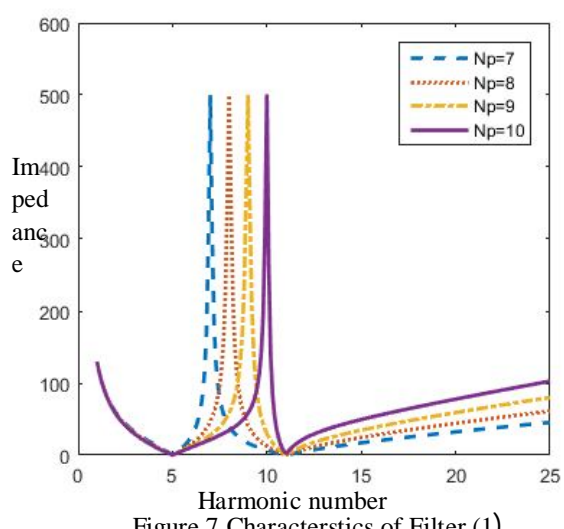

Figure.7.Characterstics of Filter (1)

The filter-1 has been formed by inserting the damped resistance in parallel with the parallel branch of simple double tuned filter. The characteristics of Filter (1) damped type double tuned filter will depend upon the resistor $\mathrm{R}$ value

1. if $\mathrm{R}=0$ then the resistance branch is short circuited and the damped type double tuned filter will act as single tuned filter at some resonant frequency, this resonant frequency will depend up on the modelled series filter elements of damped type double tuned filter.

2. If $\mathrm{R}$ is finite value then then the impedance of the damped type double tuned filter will be in the order of that $\mathrm{R}$ value. The value of $\mathrm{R}$ must be chosen like it should be more.

3. If $\mathrm{R}$ is infinite then the resistance branch is open circuit then it will act as a simple double tuned filter.

From figure.7. It is clear that impedance of filter (1) is in order of $\mathrm{R}=500 \mathrm{ohms}$ at every order of parallel resonance frequency $7^{\text {th }}, 8^{\text {th }}, 9^{\text {th }}$ and $10^{\text {th }}$. So it is concluded that impedance of filter (1) is on the order of R at $\omega_{p}$. The voltage harmonic distortions after installation of filter (1) by selecting the interested parallel resonance frequency are tabulated in Table.6.

Volume 8 Issue 3 June 2017

ISSN: 2319-1058 
Table.6. Impact of filter (1) on $33 \mathrm{kV}$ bus

\begin{tabular}{|c|c|c|c|c|c|c|c|}
\hline \multicolumn{8}{|c|}{$\%$ voltage harmonic distortions by changing the parallel resonance } \\
\hline Parallel resonance frequency order & Total & $5^{\text {th }}$ order & $7^{\text {th }}$ order & $11^{\text {th }}$ order & $13^{\text {th }}$ order & $17^{\text {th }}$ order & $19^{\text {th }}$ order \\
\hline 7 & 4.7037 & $\mathbf{0 . 2 3}$ & 3.8137 & 0.056 & 1.1619 & 1.692 & 1.8199 \\
\hline 8 & 4.4836 & 0.1455 & 3.076 & 0.1473 & 1.5074 & 1.9848 & 2.0944 \\
\hline 9 & 4.6367 & 0.0725 & 2.7176 & 0.2991 & 1.8848 & 2.2452 & 2.3292 \\
\hline 10 & 4.9306 & 0.0201 & 2.5097 & 0.519 & 2.2893 & 2.4726 & 2.5274 \\
\hline
\end{tabular}

Filter (2) is formed by inserting the damping resistor in double tuned filter as shown in figure.8.

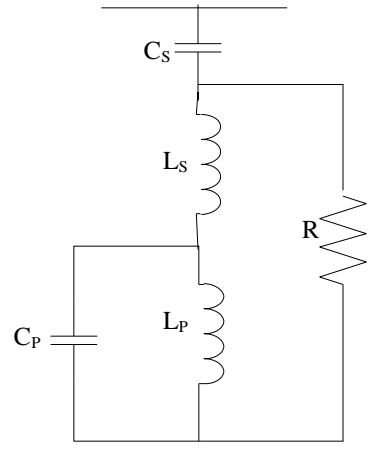

Figure.8. Filter (2)

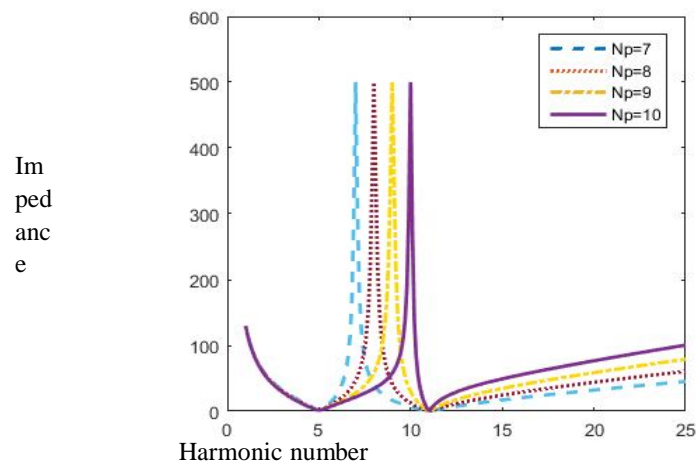

Figure.9.Characterstics of Filter (2)

For filter (2) the resistance (R) value has been chosen 500 ohms to satisfy the relation $\mathbb{R}>\sqrt{L_{1} / L_{1}}$.the impedance the impedance takes $500 \mathrm{ohms}$ as asymptotic line when $\omega$ is more than $11^{\text {th }}$ order frequency.it has been concluded that In filter (2) the impedance takes $\mathrm{R}$ as asymptotic line when $\omega$ is more than $\omega_{2}$. The voltage harmonic distortions after installation of filter (2) is tabulated in Table.7.

Table.7. Impact of filter (2) on $33 \mathrm{kV}$ bus

\begin{tabular}{|c|c|c|c|c|c|c|c|}
\hline \multicolumn{8}{|c|}{ \% voltage harmonic distortions by changing the parallel resonance } \\
\hline Parallel resonance frequency order & Total & $5^{\text {th }}$ order & $7^{\text {th }}$ order & $11^{\text {th }}$ order & $13^{\text {th }}$ order & $17^{\text {th }}$ order & $19^{\text {th }}$ order \\
\hline 7 & 4.7237 & 0.6291 & 3.8163 & 0.0609 & 1.1545 & 1.6723 & 1.7946 \\
\hline 8 & 4.4857 & 0.6324 & 3.0665 & 0.0613 & 1.4964 & 1.9575 & 2.0599 \\
\hline 9 & 4.6154 & 0.6365 & 2.7021 & 0.0617 & 1.8681 & 2.2093 & 2.2851 \\
\hline 10 & 4.8737 & 0.6393 & 2.491 & 0.062 & 2.263 & 2.4277 & 2.4739 \\
\hline
\end{tabular}

Filter (3) is formed by inserting the damping resistor in double tuned filter as shown in figure.10.

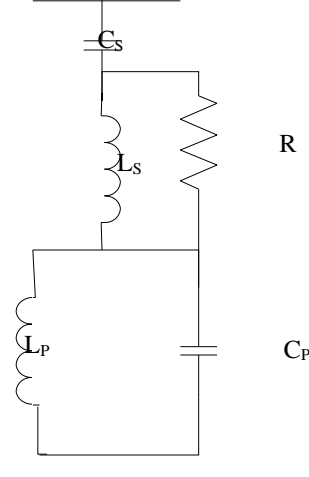

Figure.10. Filter (3)

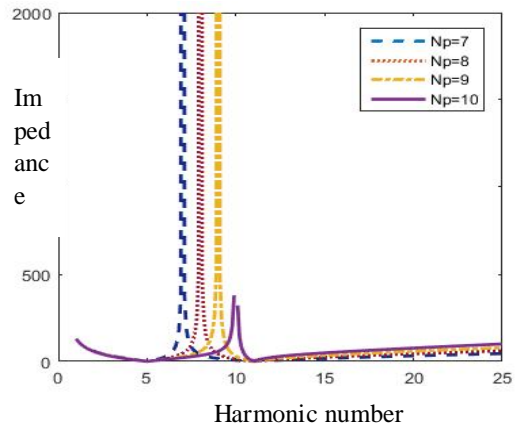

Figure.11.Characterstics of Filter (3) 
The impedance of the filter(c) reaches the infinite value at each and every order of parallel resonance frequency $7^{\text {th }}, 8^{\text {th }}, 9^{\text {th }}$ and $10^{\text {th }}$. The impedance of filter (c) at $\omega_{p}$ is very large but the impedance above $\omega_{2}$ is in the order of R. The voltage harmonic distortions after installation of filter (3) is tabulated in Table.8.

Table.8. Impact of filter (3) on $33 \mathrm{kV}$ bus

\begin{tabular}{|c|c|c|c|c|c|c|c|}
\hline \multicolumn{7}{|c|}{$\%$ voltage harmonic distortions by changing the parallel resonance } \\
\hline Parallel resonance frequency order & Total & $5^{\text {th }}$ order & $7^{\text {th }}$ order & $\mathbf{1 1}^{\text {th }}$ order & $\mathbf{1 3}^{\text {th }}$ order & $\mathbf{1 7}^{\text {th }}$ order & $\mathbf{1 9}^{\text {th }}$ order \\
\hline 7 & 4.7024 & $\mathbf{0 . 1 0 8}$ & 3.8405 & $\mathbf{0 . 2 2 9 2}$ & 1.1507 & 1.666 & 1.7886 \\
\hline 8 & 4.4647 & $\mathbf{0 . 1 8 3}$ & 3.0872 & $\mathbf{0 . 3 8 7}$ & 1.4879 & 1.9484 & 2.0516 \\
\hline 9 & 4.6142 & $\mathbf{0 . 2 9 2 9}$ & 2.7156 & $\mathbf{0 . 6 0 7 1}$ & 1.8549 & 2.1996 & 2.2767 \\
\hline 10 & 4.9237 & $\mathbf{0 . 4 4 3 7}$ & 2.4967 & $\mathbf{0 . 8 9 2 5}$ & $\mathbf{2 . 2 5 0 1}$ & 2.4209 & 2.4682 \\
\hline
\end{tabular}

Filter (4) is formed by inserting the damping resistor in double tuned filter as shown in figure.12.

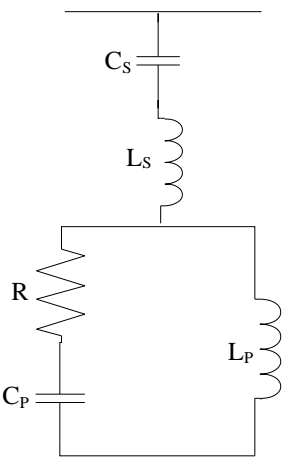

Figure.12. Filter (4)

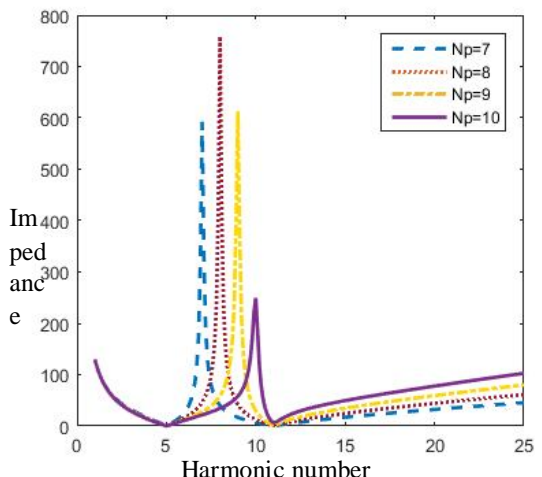

Figure.13.Characterstics of Filter (4)

The damping resistor value in Filter (D) is very less because the resistor is connected in series with the reactive element. Filter (D) behaves as a high pass filter. The voltage harmonic distortions after installation of filter (3) is tabulated in Table.9.

Table.9.Impact of filter (4) on $33 \mathrm{kV}$ bus

\begin{tabular}{|c|c|c|c|c|c|c|c|}
\hline \multicolumn{8}{|c|}{ \% voltage harmonic distortions by changing the parallel resonance } \\
\hline Parallel resonance frequency order & Total & $5^{\text {th }}$ order & $7^{\text {th }}$ order & $1^{\text {th }}$ order & $1^{\text {th }}$ order & $17^{\text {th }}$ order & $19^{\text {th }}$ order \\
\hline 7 & 4.6774 & 0.2478 & 3.7758 & $\mathbf{0 . 2 8 2 4}$ & 1.1596 & 1.6863 & 1.8145 \\
\hline 8 & 4.4851 & $\mathbf{0 . 0 3 7 7}$ & 3.0826 & $\mathbf{0 . 1 8 3 1}$ & 1.5053 & 1.9831 & 2.0928 \\
\hline 9 & 4.64 & $\mathbf{0 . 0 1 8 3}$ & 2.7207 & $\mathbf{0 . 3 6 2}$ & 1.8824 & 2.2436 & 2.3278 \\
\hline 10 & 5.0222 & $\mathbf{0 . 0 1 0 2}$ & $\mathbf{2 . 5 0 9 6}$ & 1.1025 & 2.2852 & 2.4709 & 2.5261 \\
\hline
\end{tabular}

Filter (5) is formed by inserting the damping resistor in double tuned filter as shown in figure.14.

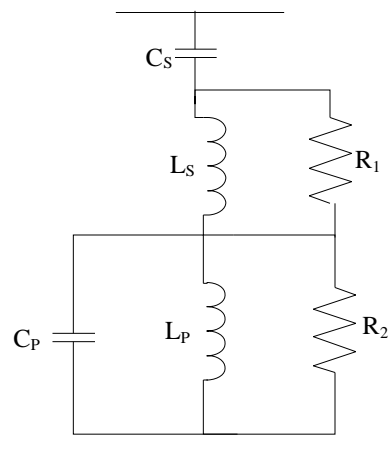

Figure.14. Filter (5)

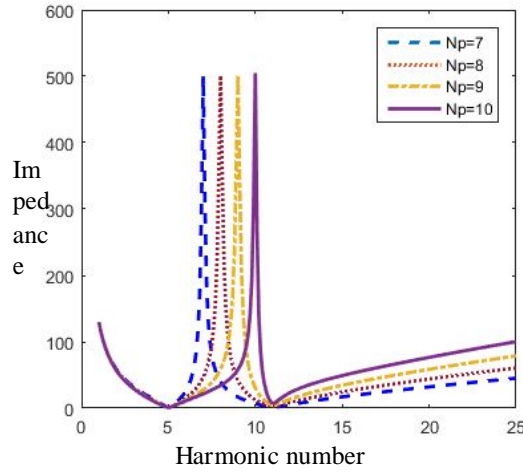

Figure.15.Characterstics of Filter (5) 
The resistance $\left(\mathrm{r}_{1}\right)$ value for filter(5) has been taken as 500ohm in order to satisfy the relation of $R_{1}>\sqrt{L_{1} / C_{1}}$, the impedance of the filter(5) is limited to the resistance values at $11^{\text {th }}$ order and above $11^{\text {th }}$ order .it is concluded that Filter (5) has limited impedance at $\omega_{\mathrm{p}}$ and also above $\omega_{2}$. The voltage harmonic distortions after installation of filter (5) is tabulated in Table. 10.

Table.10.Impact of filter (5) on $33 \mathrm{kV}$ bus

\begin{tabular}{|c|c|c|c|c|c|c|c|}
\hline \multicolumn{8}{|c|}{ \% voltage harmonic distortions by changing the parallel resonance } \\
\hline Parallel resonance frequency order & Total & $5^{\text {th }}$ order & $7^{\text {th }}$ order & $1^{\text {th }}$ order & $1^{\text {th }}$ order & $17^{\text {th }}$ order & $19^{\text {th }}$ order \\
\hline 7 & 4.6942 & $\mathbf{0 . 3 3 3 5}$ & 3.8137 & $\mathbf{0 . 2 8 2}$ & 1.1518 & 1.6658 & 1.7884 \\
\hline 8 & 4.4781 & $\mathbf{0 . 3 2 4 8}$ & $\mathbf{3 . 0 7 4 9}$ & $\mathbf{0 . 5 1 9 5}$ & 1.4899 & 1.9481 & 2.0514 \\
\hline 9 & 4.6564 & $\mathbf{0 . 3 6 2 4}$ & $\mathbf{2 . 7 1 1 6}$ & $\mathbf{0 . 8 5 4 8}$ & 1.8569 & 2.1994 & 2.2765 \\
\hline 10 & 5.0076 & $\mathbf{0 . 4 6 2 4}$ & $\mathbf{2 . 4 9 6 3}$ & 1.2703 & 2.2506 & 2.4209 & 2.4681 \\
\hline
\end{tabular}

Filter (6) is formed by inserting the damping resistor in double tuned filter as shown in figure.16.

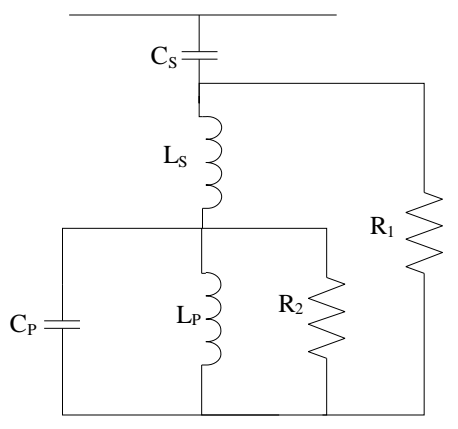

Figure.16. Filter (6)

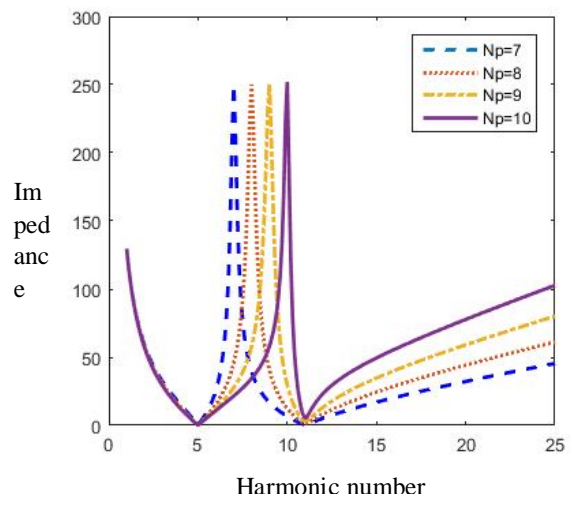

Figure.17.Characterstics of Filter (6)

Impedance of filter $(\mathrm{F})$ is limited to $250 \mathrm{ohms}$ which is the lower value of $\mathrm{R}_{1}$ and $\mathrm{R}_{2}$ both at frequency order $7^{\text {th, }}$ $8^{\text {th }}, 9^{\text {th }}$ and $10^{\text {th }}$ and above $11^{\text {th }}$ order. Hence it is concluded that the Impedance filter $(6)$ is limited to the lower value of $R_{1}$ and $R_{2}$ both at $\omega_{\mathrm{p}}$ and above $\omega_{2}$. The voltage harmonic distortions after installation of filter (6) is tabulated in Table.11.

Table.11. Impact of filter (6) on $33 \mathrm{kV}$ bus

\begin{tabular}{|c|c|c|c|c|c|c|c|}
\hline \multicolumn{8}{|c|}{ \% voltage harmonic distortions by changing the parallel resonance } \\
\hline Parallel resonance frequency order & Total & $5^{\text {th }}$ order & $7^{\text {th }}$ order & $11^{\text {th }}$ order & $13^{\text {th }}$ order & $17^{\text {th }}$ order & $19^{\text {th }}$ order \\
\hline 7 & 4.7619 & 1.0377 & 3.7723 & 0.1703 & 1.153 & 1.6712 & $\mathbf{1 . 7 9 3 8}$ \\
\hline 8 & 4.5262 & 0.8936 & 3.0457 & 0.3446 & 1.493 & 1.9558 & 2.0587 \\
\hline 9 & 4.6679 & 0.7674 & 2.6936 & 0.6189 & 1.8631 & 2.2077 & 2.2841 \\
\hline 10 & 4.9725 & 0.6758 & 2.489 & 0.9803 & 2.2593 & 2.427 & 2.4735 \\
\hline
\end{tabular}

As per [1] the voltage individual harmonic distortion limits for $33 \mathrm{kV}$ bus should be $3 \%$. The voltage individual harmonic distortion limits caused by the $5^{\text {th }}$ and $11^{\text {th }}$ harmonics has been eliminated with the usage of basic double tuned filter. By adding a damped resistor to the double tuned filter the total voltage harmonic distortion is further reduced as compared to basic double tuned filter. It is concluded that with the variation of the parallel resonance frequency order in between the $5^{\text {th }}$ and $11^{\text {th }}$ the harmonic content produced by the intermediate harmonics i.e., $7^{\text {th }}$ harmonic is also reduced and as a result the total harmonic content in the test system is also reduced. The individual voltage harmonic distortions due $7^{\text {th }}$ order harmonic also significantly reduced by increasing the parallel resonance frequency order from $7^{\text {th }}$ to $10^{\text {th }}$.

\section{CONCLUSION}

An algorithm to determine the parameters of different configurations of double tuned filters is proposed in this paper. With the proposed algorithm the intermediate harmonic between the tuned frequencies also reduced by changing the parallel resonance frequencies. The variation in the characteristics of damped type double tuned filter by varying the damping resistance is also explained briefly in this paper. 


\section{REFERENCES}

[1] IEEE Recommended Practices and Requirements for Harmonic Control in Electrical Power Systems," in IEEE Std 519-1992, vol., no., pp.1-112, April 9, 1993, doi: 10.1109/IEEESTD.1993.114370

[2] "The Effects of Power System Harmonics on Power System Equipment and Loads," in IEEE Transactions on Power Apparatus and Systems, vol. PAS-104, no. 9, pp. 2555-2563, Sept. 1985, doi: 10.1109/TPAS.1985.319019

[3] V. E. Wagner et al., "Effects of harmonics on equipment," in IEEE Transactions on Power Delivery, vol. 8, no. 2, pp. 672-680, Apr 1993. doi: $10.1109 / 61.216874$.

[4] I. W. GROUP, "IV, B. Power Line Harmonic Effects on Communication Line Interference," in IEEE Transactions on Power Apparatus and Systems, vol. PAS-104, no. 9, pp. 2578-2587, Sept. 1985.doi: 10.1109/TPAS.1985.319023

[5] IEEE Recommended Practice for Industrial and Commercial Power Systems Analysis (Brown Book)," in IEEE Std 399-1997, vol., no., pp.1-488, Aug. 31 1998. doi: 10.1109/IEEESTD.1998.88568

[6] G. J. Wakileh, Power Systems Harmonics, First Edition, Springer, 2001

[7] J. Arillaga, D. A. Bradely, P. S. Bodger, Power System Harmonic, John Willy \& Sons Ltd, 1985

[8] Xiao Yao, "Algorithm for the parameters of double tuned filter," 8th International Conference on Harmonics and Quality of Power. Proceedings (Cat. No.98EX227), Athens, 1998, pp. 154-157 vol.1. doi:10.1109/ICHQP.1998.759869. 